\title{
Training patients in Time Pressure Management, a cognitive strategy for mental slowness
}

Citation for published version (APA):

Winkens, I., van Heugten, C. M., Wade, D., \& Fasotti, L. (2009). Training patients in Time Pressure Management, a cognitive strategy for mental slowness. Clinical Rehabilitation, 23(1), 79-90.

https://doi.org/10.1177/0269215508097855

Document status and date:

Published: 01/01/2009

DOI:

10.1177/0269215508097855

Document Version:

Publisher's PDF, also known as Version of record

Document license:

Taverne

Please check the document version of this publication:

- A submitted manuscript is the version of the article upon submission and before peer-review. There can be important differences between the submitted version and the official published version of record.

People interested in the research are advised to contact the author for the final version of the publication, or visit the DOI to the publisher's website.

- The final author version and the galley proof are versions of the publication after peer review.

- The final published version features the final layout of the paper including the volume, issue and page numbers.

Link to publication

\footnotetext{
General rights rights.

- You may freely distribute the URL identifying the publication in the public portal. please follow below link for the End User Agreement:

www.umlib.nl/taverne-license

Take down policy

If you believe that this document breaches copyright please contact us at:

repository@maastrichtuniversity.nl

providing details and we will investigate your claim.
}

Copyright and moral rights for the publications made accessible in the public portal are retained by the authors and/or other copyright owners and it is a condition of accessing publications that users recognise and abide by the legal requirements associated with these

- Users may download and print one copy of any publication from the public portal for the purpose of private study or research.

- You may not further distribute the material or use it for any profit-making activity or commercial gain

If the publication is distributed under the terms of Article $25 \mathrm{fa}$ of the Dutch Copyright Act, indicated by the "Taverne" license above, 


\title{
Training patients in Time Pressure Management, a cognitive strategy for mental slowness
}

\author{
leke Winkens Vilans, Hoensbroek and School for Mental Health and Neurosciences, Maastricht University, \\ Caroline M Van Heugten School for Mental Health and Neurosciences, Maastricht University and Centre of Excellence in \\ Rehabilitation De Hoogstraat, Rudolf Magnus Institute, Utrecht, Derick T Wade Vilans, Hoensbroek; School for Mental Health \\ and Neurosciences, Maastricht University, The Netherlands; and Oxford Centre for Enablement, Oxford, UK and \\ Luciano Fasotti Sint Maartenskliniek Research, Development \& Education and NICl, Nijmegen Institute for Cognition and \\ Information, Nijmegen, The Netherlands
}

Received 18th April 2008; returned for revisions 20th July 2008; revised manuscript accepted 16th August 2008.

Purpose: To provide clinical practitioners with a framework for teaching patients Time Pressure Management, a cognitive strategy that aims to reduce disabilities arising from mental slowness due to acquired brain injury. Time Pressure Management provides patients with compensatory strategies to deal with time pressure in daily life. Application of the training in clinical practice is illustrated using two case examples from a randomized controlled trial on the effectiveness of Time Pressure Management for patients with stroke.

Rationale: The Time Pressure Management approach is based on Michon's task analysis, describing levels of decision-making in complex cognitive tasks. Decisions with little or no time pressure are not impaired by mental slowness. Therefore, patients should try to transfer actions from situations with high time pressure to situations where the preserved decision levels with little or no time pressure can work.

Theory into practice: Several factors are required to teach patients to use Time Pressure Management. First, sufficient awareness is needed to recognize that there is a deficit and behavioural change is necessary. Sufficient awareness is also required to recognize and anticipate time pressure situations and to realize that the strategy is helpful and might also be useful in new and more difficult circumstances. Second, adequate motivation is needed to learn the strategy. And finally, the training should be adjusted to the patient's individual learning abilities and cognitive skills.

\section{Introduction}

Mental slowness is a common complaint after acquired brain damage due to stroke or traumatic brain injury. ${ }^{1-4}$ Patients may present with a wide

Address for Corespondence: I Winkens, Vilans, PO Box 192, 6430 AD Hoensbroek, The Netherlands. e-mail: i.winkens@vilans.nl range of problems and complaints. There may be an externally observed slowness: patients may show slowed performance on neuropsychological tasks, and they may have problems with everyday situations where events proceed at a rate they cannot control, such as in conversations, driving a car and watching television. ${ }^{5}$ There may be an internal feeling of slowness that things happen too quickly, so that one can no longer keep up 
mentally with cognitive demands being made by external events, which may lead to feelings of fatigue, altered mood, irritability etc.

HB, a 43-year-old man, suffered a stroke. Four months later he still noticed a decreased tempo in performing computer work or household tasks, experienced time pressure during conversations and felt that there was always too little time to perform his daily chores. $H B$ felt extremely fatigued and even agitated when performing these tasks.

MA, a 58-year-old woman teacher, was first seen eight months after a subarachnoid haemorrhage complicated by a cerebral infarction. She was fully independent in personal activities and wished to return to teaching. She did not foresee any difficulties with this. Her treating psychologist, however, noticed that MA was not able to participate in conversations and was not able to perform several tasks in a short amount of time. $M A$ 's family reported that she retreated from social activities she had enjoyed before (like making visits and going to birthday parties). Her treating psychologist therefore suggested Time Pressure Management training.

In this paper we present a strategy training for reducing problems associated with (a feeling of) mental slowness. Strategy training is not aimed at restoring a lost neuropsychological process or function, but at improving the performance of patients within their possibilities and thus reducing their complaints. Patients are taught compensatory strategies that should enable them to maximize activities and participation and to function more independently in daily life, despite the lasting presence of a cognitive deficit. Strategy training has been applied with success in the areas of memory, attention, apraxia and problem-solving in stroke patients as well as traumatic brain injury patients. ${ }^{6-9}$

Fasotti and co-workers developed and evaluated the so-called Time Pressure Management training. ${ }^{10}$ It consists of two sorts of cognitive strategies by which subjects either learn to 'prevent' or to 'manage' time pressure, and hence compensate for their slowness and deal with the task at hand. The idea is that Time Pressure Management training is applicable to every problem caused by mental slowness.
The training was initially developed for adults who had sustained a traumatic brain injury. However, it is likely that the training is beneficial also for adults with mental slowness resulting from other causes, such as stroke or multiple sclerosis. The training can be applied to both outpatients and inpatients. However, to recognize deficits and the need for treatment, patients should have had some experiences with time pressure in their own daily lives. Consequently, most patients receiving Time Pressure Management are in the subacute or chronic phase after brain injury.

Time Pressure Management training is usually given in sessions of one hour per week, with a maximum of $8-12$ hours. We think that the training should be given either by a psychologist, or by a cognitive or occupational therapist under the supervision of a psychologist. Brain-injured patients are often confronted with a complex profile of impairments and comorbidities, and simply applying a standard treatment protocol is hardly ever possible. Individualized adjustments are usually necessary.

This paper draws on evidence and on our experience gathered in a randomized controlled trial, and provides suggestions on how Time Pressure Management training should be given. First, we will describe the rationale behind the training, and briefly explain its content. Then we will describe in detail how the training should be given, illustrated by two cases extracted from the trial.

\section{Rationale behind Time Pressure Management}

For any task, decision-making can be hierarchically ordered into three levels, differing in the amount of time pressure present. ${ }^{11}$ The first level, the 'strategic level', concerns decisions (and subsequent actions) that can be undertaken well beforehand. When driving a car for instance, decisions are made with regard to the route and time of departure. For these decisions there is usually enough time and no time pressure is experienced. The second level is the 'tactical level', which relates to anticipating events and adapting behaviour before time pressure builds up. To stay with the example of car driving, both the driving speed and distance between the car and the vehicle in 
front might be adapted at a tactical level. At this level time pressure is present but usually still manageable. The third level is the 'operational level', where immediate decisions and actions are required to prevent failure and risks. For example hitting the brakes and turning the wheel to avoid a collision, or reacting to sudden deviations and to manoeuvre the car through traffic are operational actions. Here much time pressure is felt.

The basic idea is that the strategic and tactical decision levels are not impaired by mental slowness and that one can strongly reduce time pressure at the operational level by using the preserved ability to take strategic and tactical decisions. In other words, Time Pressure Management training focuses on the reorganization of the execution of tasks. By breaking up a time pressure task into subtasks and subsequently identifying the amount of time pressure in these subtasks, one can pinpoint decisions and actions that can prevent (strategic) or manage (tactical) time pressure. Patients are taught to shift as many actions as possible from the impaired levels with high time pressure to the preserved levels with little or no time pressure.
This should minimize the negative consequences of mental slowness and should lead to improvements in task performance. Returning to the driving example for instance, patients may be taught to take strategic decisions, such as leaving on time, or tactical decisions, such as keeping ample distance and not driving too fast. This should give the patient enough time to react in tricky traffic circumstances and even prevent the occurrence of dangerous situations in the first place.

The training is given in three main stages (Table 1). The remainder of this article will describe in detail how the training should be administered.

\section{Time Pressure Management training}

\section{Stage 1: Identifying the problem}

Although we will not present fixed selection criteria on how people should be selected for Time Pressure Management training, there are some factors that need to be taken into account. The first vital step for both the therapist and the patient is to become aware that mental slowness

Table 1 Time Pressure Management. Stages, components, and prerequisites

\begin{tabular}{|c|c|c|c|}
\hline Stages & Components & Stage-specific prerequisites & Can be achieved by \\
\hline $\begin{array}{l}\text { Stage 1: } \\
\text { Identifying the } \\
\text { problem }\end{array}$ & Diagnosis of mental slowness & Awareness of therapist & $\begin{array}{l}\text { Neuropsychological tests } \\
\text { Mental Slowness } \\
\text { Questionnaire } \\
\text { Mental Slowness Observation } \\
\text { Test } \\
\text { Feedback and demonstration } \\
\text { Practice, explanation and } \\
\text { feedback }\end{array}$ \\
\hline $\begin{array}{l}\text { Stage 2: } \\
\text { Teaching the } \\
\text { strategy }\end{array}$ & $\begin{array}{l}\text { Patient learning the strategy } \\
\text { Analyse the task for time } \\
\text { pressure } \\
\text { Make a plan of decisions and } \\
\text { actions to undertake before the } \\
\text { task starts } \\
\text { Make an emergency plan } \\
\text { Execute the task and monitor } \\
\text { Apply the strategy }\end{array}$ & $\begin{array}{l}\text { Anticipatory awareness and } \\
\text { emergent awareness } \\
\text { Sufficient learning ability } \\
\text { Adequate cognitive skills } \\
\text { Enough rest } \\
\text { Sufficient motivation }\end{array}$ & $\begin{array}{l}\text { Distributed practice } \\
\text { Meaningful and personalized } \\
\text { information and examples }\end{array}$ \\
\hline $\begin{array}{l}\text { Stage 3: } \\
\text { Generalization }\end{array}$ & $\begin{array}{l}\text { Apply the strategy in new and } \\
\text { more difficult situations }\end{array}$ & Sufficient cognitive skills & $\begin{array}{l}\text { Practice, feedback and } \\
\text { demonstration }\end{array}$ \\
\hline
\end{tabular}


is such a critical problem that many activities are adversely affected by the inability to react to external events at a speed that is necessary or that is felt to be appropriate by the patient. Mental slowness may bring about secondary problems such as emotional changes, fatigue or forgetfulness and it is important that the patient and therapist are aware of this so that Time Pressure Management training might be considered if so.

Therapists need to be aware that mental slowness may be present, even if the patient does not complain about it directly. Mental slowness may for example explain why patients fail at tasks that otherwise seem within their capability, or why they experience undue fatigue, or emotional disturbances such as irritability or anxiety.

Once the problem is suspected one possible diagnostic response is to administer standardized neuropsychological tests such as the Symbol Digit Modalities Test, Paced Auditory Serial Addition Task or Trail Making Test. ${ }^{12}$ However, the relationship between slowness as measured by such tests and the performance of the patient in daily life activities may be very weak. ${ }^{13}$ In addition, objectively measured slowness is not necessarily concurrent with experienced slowness.

Therefore it is essential for the therapist to assess both the patient's perception of slowness and to assess his or her performance in daily situations as well. A simple questionnaire, specifically developed to assess the patient's perception of slowness, is the Mental Slowness Questionnaire in which the patient rates 21 items such as 'It takes longer before I understand what someone is saying' or 'I lose control when I am in traffic'. ${ }^{14}$

$H B$ performed at an average level on a simple reaction time task. However, assessment with the Mental Slowness Questionnaire revealed a score of 56 out of 168, meaning that he experienced slowness in quite a few daily life situations. His main complaints were: 'I need more time to understand what people are saying, for example in a meeting or on the phone', 'I need more time to understand what I am reading', 'It takes longer to come up with the right phone numbers, words, or people's names', 'I have to think tasks through, I can no longer perform them automatically', 'I need more time for doing my work or running the household', 'I am easily distracted in a busy pub or store', 'I get tired quickly because everything seems to go so fast.'

A simple means to quantify both speed and errors on some familiar everyday tasks affected by mental slowness is the Mental Slowness Observation Test. $^{14}$ This is a semi-structured observation of four tasks:

1) Following instructions on a route

2) Obtaining train times by telephone

3) Sorting money

4) Looking up telephone numbers.

$H B$ performed poorly on the Mental Slowness Observation Test. When following instructions on a route, he could not keep up with the high rate with which information was presented. He seemed overwhelmed and forgot to write down the information or ask for clarification or repetition. The same thing happened when he tried to obtain train times by telephone: again he was taken by surprise by the large amount of information given and the operator's speech rate. As a consequence, $H B$ could not report any of the information given to him.

The patient also needs to be aware of his problems, because sufficient awareness is an important first step for patients to benefit from compensation therapies like Time Pressure Management. ${ }^{15}$ Trying to teach a patient compensatory strategies can be very frustrating for the patient when they have insufficient or no awareness that there is a problem.

Unfortunately, patients may be unaware of or unconcerned about deficits after an acquired brain injury. ${ }^{15,16}$ First, unawareness may occur because information and feedback on performance have never been provided. Psychological denial also may interfere: patients may deny their problems or defend themselves against awareness because the deficits are too threatening or the deficits and strategies do not fit into the patient's self-concept or lifestyle. ${ }^{15-17}$ And third, there may be an organic or neurological reason: damage to regions 
in the brain responsible for integrating information about ourselves may lead to inaccurate selfreflections. ${ }^{16}$ Damage to these same regions can also impair cognitive skills such as memory and abstract reasoning, leading to an inability to integrate past experiences, to apply this information into real-world consequences and to learn about deficiencies. ${ }^{16,18}$

Neuropsychological test results sometimes may give the first clue that unawareness is present. But more frequently, discrepancies between a patient's actual and predicted performance, the lack of spontaneous error correction and astonished reactions to feedback may draw attention to a lack of unawareness in the patient. ${ }^{16,18}$

$M A$ reported no complaints on the Mental Slowness Questionnaire, and predicted she would not experience any time pressure or slowness in daily life tasks. On observing her performance on the Mental Slowness Observation Test however, it appeared she could not keep up with the high rate with which information was given and consequently could not report back all that was told. Unfortunately she did not seem to be aware of that. When feedback was given, MA appeared to be astonished and very disappointed about her poor task performance.

If a patient seems to be aware of a problem but denies it, psychotherapy of some sort might be needed. ${ }^{15}$ However, awareness of impaired performance ultimately follows on from feedback on performance at various tasks. Intensive explanation, coaching and demonstration is sometimes needed, because, before progress can occur, patients must understand that some daily activity is impaired. A discussion of the neuropsychological test results with the patient, showing him or her that deficits are present, may help. Alternatively, to help a patient increase awareness of deficit, the therapist can ask the patient to predict his or her own task performance and afterwards compare the predicted performance to the actual performance. $^{16,18}$

Sometimes it may help to explain the concepts of slowed information processing and mental slowness and how they may arise after brain damage. Finally, the patient should understand that slowness is a common thread in activities that are impaired, and that this has negative implications for everyday functioning. For example, the therapist may draw a patient's attention to the fact that the patient always has difficulty in following conversations in various settings. ${ }^{15}$

Throughout the counselling process, the information and examples provided to the patient should be meaningful and personalized in order to engage them in treatment. Examples of situations from the patients' own lives should be used to explain when and where time pressure may occur and how slowness affects performance in these situations. ${ }^{16}$ Only then will patients be motivated and acknowledge need for the treatment necessary to learn self-corrective procedures.

During the first week of the training, $H B$ registered the kind of time pressure situations he encountered at home. In particular he reported having difficulties watching television and making telephone calls. He usually could not remember much afterwards. It was explained to him that, due to his slowed information processing, he now needed more time to adequately process and store incoming information. However, more time is usually not given, so that to $H B$ it seems as if a movie was being played fast forward. This caused him to miss parts of, for example, a television show or a conversation.

The goals set during training should be consistent with the patient's wishes, because otherwise motivation might be low. ${ }^{16}$ Therefore it is important to consider specific goals for the patient and the process of goal-setting with the patient may further increase awareness.

The goals need to be clear, specific and realistic. ${ }^{18}$ 'Not experiencing any time pressure' is not a realistic goal; everyone experiences time pressure sometimes, for example when driving through heavy traffic, or when having to finish work within a given deadline. Examples of personal goals can be: 'I want to be able to make telephone calls, give appropriate responses and know what I need to know afterwards'; or 'I want to stay calm in unexpected situations and deal with them', or 'I want to be able to finish my work within given deadlines and not be distracted'. 
However, adequate goal-setting cannot be expected from all patients. ${ }^{19}$ Sometimes therapists need to guide clients' attention to activities or situations that are troublesome. Keeping track of errors and performance may help identify goals. ${ }^{20}$

Time spent in stage 1 (and the next stages) might differ from patient to patient and it is important to adjust this stage to the patients' individual levels. For some patients more time needs to be spent in stage 1 before awareness is increased sufficiently to proceed to stage 2 .

\section{Stage 2: Teaching the strategy}

The second stage of Time Pressure Management focuses on teaching the patient strategies. Patients are told from the outset that the speed of information processing is not expected to return to premorbid levels, but that they will learn to use a strategy to deal with their slowness. They should be repeatedly informed that the strategies aim to give them enough time to deal with the task at hand so that time pressure is prevented or handled, which can lead to satisfying performance. The patients should be reminded that their priority is always 'Let me give myself enough time to do the task.'

A short variant of the self-instruction method can be used to trigger the recollection and the use of the strategy. ${ }^{21}$ First the therapist should introduce the four steps of the strategy. It is wise for the trainer to demonstrate and explain aloud how a fairly easy task should be performed while using the strategy, for example preparing a meal.

The patient should learn that his or her first concern is to analyse the task for time pressure and identify where the preventing or handling strategies might help: 'Are there two or more things to be done at the same time for which there is not enough time?'; 'Could I be overwhelmed or distracted?'. For example, when preparing a meal, several things have to be done at the same time: washing and cutting up ingredients, watching several pans, reading the recipe, etc. If there are no time pressure actions, then the activity is unlikely to need further use of the strategy.

Next the patient should learn to identify which decisions can be taken and which actions can be performed before actually starting the activity, and to make a plan to undertake these preparatory tasks. This plan may contain any decision or action that reduces time pressure (e.g. optimizing the task environment, making sure there is no need to do several things at once, etc.). When preparing a meal the plan may, for example, consist of reading the recipe thoroughly before actually starting to cook, making sure all ingredients are washed and cut beforehand, and turning off the phone to prevent distraction. These tasks should then be executed, so that the person is ready to undertake the activity.

However, the patient should also be taught to make emergency plans for anything unexpected that may arise during the activity. These emergency plans should list all the actions that could be taken in case of overwhelming time pressure. For example, the patient could consider how he or she will react when the telephone rings while cooking - simply answer it, ignore it, or is it better to turn off the cooker and then answer it? Does the patient have an answerphone? (For detailed examples of plans and emergency plans, containing preventing or handling decisions and actions in relation to specific everyday tasks, see Table 2).

Finally, the patient needs to learn how to monitor performance; did the patient succeed in executing the task successfully, did any emergency plans work, what went wrong?

Once the overall strategy has been taught, the patient must learn and memorize the four steps (analysing time pressure, preventing time pressure, handling time pressure, monitoring task performance), initially using a memory card with the four rules of Time Pressure Management in written form. In practice the therapist will regularly remind the patient about all four steps, while focusing on training one particular aspect. Only when the patient has memorized the four steps should actual practice begin. Practice should start with fairly easy tasks, such as having a conversation or watching the news, and then proceed with more difficult tasks, ranging from conversations where the patient is distracted to cooking a meal or driving a car.

$H B$ 's first experience with the strategy is a good example of how a fairly easy task, getting information from a travel agency, can be performed 
Table 2 Examples of plans and emergency plans, containing preventing and handling decisions or actions

\begin{tabular}{ll}
\hline Example 1: & Before leaving: study the route so that no sudden \\
Driving a car & $\begin{array}{l}\text { decisions have to be made or discussions have to be } \\
\text { held while driving; leave on time, so that you will not } \\
\text { have to hurry, or worry that you will be late }\end{array}$ \\
& \\
& During driving: turn off the radio so that you will not be \\
& distracted; ask passengers not to distract you with \\
& road signs etc.; keep ample distance to the cars in \\
& front of you so that you can see what is happening \\
& further along the road and that you have enough time \\
& to react; do not drive too fast
\end{tabular}

Example 2:

Cooking a meal

Example 3:

Retrieving

information at a

travelling agency
Before starting to cook: read the recipe thoroughly, so that you know what has to be done and in which order, and how much time it will take you to cook the meal; decide which things can be done first, before putting on the stove; open cans and wrappings and put everything within arms reach; wash the vegetables and cut them; turn off the phone to prevent distraction

During cooking: do not be distracted by other things; do not leave the stove to watch television or read a magazine when you have to wait a few minutes (for example when waiting for pans to reach boiling point)

Before going to the agency. make a list of all the things you would like to know

At the agency: read through your questions while waiting for your turn; ask the employee to take you to a quiet room so that you will not be distracted, and will not feel the urge to hurry because of the queue of people behind you; during the conversation: make notes; ask the employee to speak slowly so that you can keep up with him or her
Emergency plan

In case of panic or overwhelming time pressure: move the car to the side of the road and stop. Take a break; then take another look at your plan and your preventing decisions and actions, and use them!

In case of panic or overwhelming time pressure: when the door bell rings, turn off the cooker, and then answer the door when you have to take care of two things at the same time (for example you have to pour the water of the pasta, and turn the meat over to prevent it from burning), turn off the cooker, take the pasta off the stove, pour the water off, and then start again with the meat

In case of overwhelming time pressure: ask for repetition or more information when things are not clear

Ask the employee to write the important things down for you Ask for a pause to review your questions: did you get a satisfying answer to every question? using the strategic adaptations. First, analysis of the task showed HB that several steps had to be taken to retrieve the required information. For example going to the agency, asking several questions and receiving elaborate information. Then $H B$ identified where and when time pressure might occur: he could imagine that being at the agency, where many people were talking and impatiently waiting for their turn, could lead to an overwhelming feeling of pressure and an urge to hurry up. In addition, asking several questions and receiving information at a fast rate could also be a problem and cause him to miss information or forget to ask some relevant questions. Second, $H B$ made a plan of things that could be done before the actual task started, to prevent the occurrence of time pressure. For example going to the agency during a quiet hour, or asking to sit in a quiet room, but also making a list of the most important questions that could be checked during the conversation. Third, an emergency plan was made: asking for a pause, or asking the agent to write down the most important information. And finally, the last step would require $\mathrm{HB}$ to perform 
the task and use the plan and emergency plan when necessary.

During training practice it is best for patients to instruct themselves aloud initially, guiding themselves through the strategy they have just learned. This also allows the therapist to check that the patient applies the strategies properly, and to assist the patient, giving cues and asking questions. After each task, the therapist should discuss task performance and analyse how success or failure is linked to the use of (or failure to use) the strategy. Eventually, the patient should learn to relate the quality of his or her performance to the use of the strategies while performing the task.

As a first practice, $H B$ was required to use the learned strategy during a conversation with his trainer. During the conversation he also had to deal with an unexpected situation (the telephone might ring telling him to come home to deal with an emergency). First, $H B$ analysed the task, asking himself what he was about to do and where time pressure might occur. Second, he made a plan of things he could do before the actual task began. When HB started to perform the task, the therapist interrupted, asking him if he had forgotten anything and cueing him by asking him what to do in case of overwhelming time pressure. $H B$ understood the hint and made an emergency plan. On performing the task, it appeared that, although $H B$ was very well able to create a plan and emergency plan, he forgot to actually use it. After receiving feedback from the therapist, $H B$ tried to perform the task again, now remembering to use both plans. $H B$ noticed that the strategy indeed could be of great use, leading to better task performance, and was very satisfied about his performance.

Some specific problems may arise when teaching the strategies. The patients may:

- disagree with the therapist on the utility of the strategy;

- not recognize when they need to start enforcing the strategy;

- fail to anticipate problems with time pressure;
- not learn the strategies due to fatigue and overstimulation or secondary to cognitive deficits affecting memory and concentration.

Some ways of overcoming these difficulties are given.

MA is a good example of someone who was not able to recognize that a problem would occur and the strategy should be applied. On analysing a task (having a conversation as a teacher with agitated parents about the school achievements of a student) it appeared that MA was not foreseeing any problems with having that conversation. Even when the therapist explained to her that having a conversation with two people at the same time, both probably angry, and asking many questions, would require her to process much information in a short amount of time. MA saw no need in preparing the conversation and using the strategy.

It is important to persuade the patient that success is related to the use of strategies and that failure is likely when the strategies are not used. Only then will the patient be committed to use the strategy routinely. Elaborate practice and relevant feedback on the benefits of performing tasks while using a strategic approach is a first step to increase the probability that patients will actually apply what they have learned.

In addition, for patients to achieve compensatory behaviour at a managing (tactical) level, they must be able to recognize a problem with time pressure when it happens, and subsequently initiate compensation. ${ }^{15}$ However, some patients lack this 'emergent awareness': they are able to recognize the deficit, and sometimes even explain that a strategy should be applied, but they do not recognize the need to initiate strategic behaviour. They are not able to monitor the environment or to react to feedback from others. Therapists should focus on this during training. They should teach patients how to pick up (subtle) cues that can help them to realize that they are in a time pressure situation wherein strategic adaptations are needed. In addition the therapist and patient should identify situations where it is appropriate for the patient to use a strategy and then practice these situations repeatedly. For example, 
if patients have difficulties following conversations, they should learn to detect the need to initiate the appropriate strategy as soon as they are no longer able to process the information adequately. They should learn to pick up internal (for example feelings of panic or a 'full head') as well as external cues (e.g. other people asking them whether they can understand what is being said). Therapists should teach patients that initiation of the strategy is then needed.

For patients who seem unable to learn to recognize time pressure situations, the therapist might choose to train what is called 'situational compensation' - compensating behaviour that is triggered by a specific type of circumstance. This behaviour must become a habit and must be used in all situations that fall in a critical category. For example, the patient who has difficulties following conversations should learn to use conversations as a trigger to initiate the application of strategies, even if their use is not strictly necessary at that moment. A limited number of critical situations should be practised time and again. ${ }^{15}$

Third, to achieve compensation at a preventive (strategic) level, 'anticipatory awareness' is necessary: patients must be capable of anticipating that a problem is going to occur and be aware that compensation reduces the chance that the problem will occur. Of course, this type of compensation is preferred in order to avoid and minimize problems. However, anticipatory awareness is often impaired in patients with acquired brain injury and can be very persistent. ${ }^{15}$ Fasotti and co-workers described in their paper on the effectiveness of Time Pressure Management in traumatic brain injury patients, that most patients only initiate compensation once the problem has set in. ${ }^{10}$ If patients lack the ability to anticipate, therapists may restrict themselves to teaching only managing strategies. It may be more efficient to spend the available training time on teaching them to make tactical or handling decisions, instead of spending time on teaching them strategic behaviour or preventive steps that they will never use.

In this stage it is important to realize that some other factors, such as the nature of the patient's cognitive and learning deficits, also influence the success of treatment: therapists need to make sure that patients get enough rest in between sessions, and should be aware that the response to training improves when patients are alert. To prevent overstimulation, distributed practice for short periods has been recommended not only in several studies on educational psychology and motor skill learning, but also in rehabilitation practice. ${ }^{22,23}$

In addition, therapists need to use the most effective teaching strategies. They should recognize when the patient is not responsive and when something else should be tried. ${ }^{16}$ Not every patient can be expected to learn to use compensatory strategies. ${ }^{17}$ As already reported, patients have to be able to conceptualize, to self-monitor, to recognize and realize shortcomings, and to understand the nature of the process by which improvement of performance can be achieved. This requires a substantial set of cognitive skills. ${ }^{15,16}$ For patients who do not possess these skills, it is sensible to restrict training to, for example, procedural training or environmental support. ${ }^{16}$ In those circumstances therapists can try to maximize functioning without being concerned whether the patient fully understands why a certain strategy should be used or whether generalization will occur.

\section{Stage 3: Generalization}

In the last stage of Time Pressure Management training the focus is on generalization. Patients should understand that the aim of a rehabilitation programme is to restore them to their greatest potential and maximum independence, hopefully resulting in independent functioning at home and in society. Occurrence of generalization in strategy training should not be taken for granted and the spontaneous transfer of skills is very unlikely. ${ }^{16,24}$ Generalization therefore already should receive attention during the training period and measures can be taken to facilitate it. Some of the most important measures are described here.

A prerequisite for transfer is that patients should know what transfer is, and how it works. Therapists should persuade patients that, since they cannot possibly treat all the problems and tasks patients will encounter in their own surroundings, transfer of skills and strategies from the rehabilitation setting to the home setting and from trained to non-trained tasks and situations is of great importance to the clinical success of a therapy programme. 
Second, in Time Pressure Management, general strategies are taught and patients need to learn when and where they can be applied. A variety of tasks and situations should be trained to uncouple the connection between what is learned and the situation in which it is learned. Patients need to experience and be explicitly told that the Time Pressure Management strategy is a general strategy that can be used in many different situations and tasks, even ones that were not trained. Although for each task the specific content of the plan and emergency plan has to be adapted, the same strategy can be applied in every situation in which time pressure is crucial, for instance cooking a meal or driving a car. This requires sufficient ability of abstract reasoning, because otherwise patients will only understand their problems at a concrete level, and in relation to particular circumstances. ${ }^{15}$ If patients are thought to lack this level of abstract reasoning, therapists may choose to restrict training to situations that are important for the patient and that regularly lead to problems and risks.

Finally, the training situation should be repeatedly modified to support new skills and behaviours. Practice of many different and more difficult tasks is needed, showing the patient that the strategy indeed can be used in these different tasks, and that the strategy is helpful and probably also will be in other, untrained, situations.

A final, somewhat unrelated, but equally important aspect for therapists is the recognition that some patients may feel embarrassed or even ashamed having to use strategies in situations that for other people are easy to handle. In order for patients to benefit from Time Pressure Management it is important that therapists tackle these thoughts. Therapists must stress that everyone uses these strategies regularly and that Time Pressure Management is just an extension of the strategies that non-brain-injured people use in their daily lives, such as diaries to support memory functioning.

In conclusion, Time Pressure Management should be presented as a general strategy that can be used to tackle a wide range of problem situations. With sufficient awareness and motivation, elaborate practice, the proper feedback and adjustment of the training to the individual level of the patient, even patients with severe deficits can learn to use the strategy.
$H B$ underwent a neuropsychological assessment at the start and at the end of the training (i.e. after 10 hours of training, 10 weeks later) and again three months later, using a mix of standard and experimental tests. This assessment was limited owing to the patient's physical disabilities and communication problems. His performance on the standard neuropsychological tests did not improve significantly, which was to be expected since Time Pressure Management focuses on dealing with the consequences of time pressure, not on actually restoring speed of information processing. On the Mental Slowness Questionnaire and Mental Slowness Observation Test, however, HB showed marked improvement: his complaints on the Mental Slowness Questionnaire decreased by $41 \%$ (his total score decreased from 56 to 33 on a scale from 0 to 168). He reported the same complaints, although they were less frequent and less severe. In addition his performance on the Mental Slowness Observation Test improved. Although performance was still below average, he improved more than $100 \%$, his total score increasing from 5.2 to 16 on a scale from 0 to 40.

\section{Conclusions}

In this paper we have illustrated how to teach patients about Time Pressure Management, using two case examples from a randomized controlled trial on the effectiveness of Time Pressure Management for patients with stroke. Time Pressure Management is a cognitive strategy training that aims at teaching patients compensatory strategies to facilitate the handling of time pressure in daily life that results from mental slowness due to acquired brain injury. From observations and clinical experience gathered in a randomized controlled trial we infer that several factors may be prerequisites for patients to learn and use Time Pressure Management. Other factors may complicate training patients in its use, and for some patients the Time Pressure Management training may not work.

MA also underwent a neuropsychological assessment at the start and end of the training and again 
three months later. After a training period of 10 weeks, MA's strategy use on the Mental Slowness Observation Test was almost the same as before the start of the training: when following instructions on a route or when obtaining train times by telephone she did not realize that the learned strategy would be needed for optimal performance. She did not take notes or did it insufficiently, i.e. without asking for a pause or repetition etc. Consequently she showed no or only marginal improvement on the Mental Slowness Observation Test (her total score went from 32.5 to 35.1 ).

First, each stage of the Time Pressure Management training requires an adequate level of awareness of the patient. In the first stage, awareness of errors and deficits and of the relation between mental slowness, time pressure and task performance is needed. The second and third stages of Time Pressure Management require conviction that successful task performance is related to use of the strategy. In addition, 'emergent' and 'anticipatory' awareness are needed, either to recognize a problem when it happens and then initiate compensation, or to anticipate that a problem is going to occur and then realize that compensation will reduce the chance that a problem will occur. ${ }^{15}$

A second problem encountered is that patients may not be sufficiently motivated to learn the strategy. This problem does not only apply to Time Pressure Management training, but is an important issue in every training in general. To increase a patient's motivation to learn, information and examples provided should be meaningful and personalized.

Third, Time Pressure Management training should be adjusted to the patient's individual learning abilities. For some patients, more time and practice is required before they can proceed from one stage to another. Others need more rest in between sessions. And still others may require another training approach which is more suitable for their particular needs. For example, therapists might switch to 'procedural training', where by means of repetition and practice, the patient 'overlearns' a few important skills. ${ }^{16}$

In addition, therapists should understand the patient's cognitive deficits. To learn to use the strategy, patients have to be able to integrate past experiences and apply this information to real-world situations. They have to be able to memorize the steps of the strategy and they have to generalize what they have learned to other settings and new tasks. This requires a substantial set of cognitive skills that cannot be expected from every patient. Therapists should recognize when there is no response and next try something else.

In conclusion we think that even severe patients may benefit from Time Pressure Management, if the training is adjusted to the patient's individual level of readiness, cognitive skill and awareness. However, this paper was not meant to discuss the effectiveness of Time Pressure Management and right now we can only speculate about the effects of the training for patients at an individual level. This paper was meant only to give a framework on how the training is given and which considerations the therapist might be confronted with.

Fasotti and colleagues have already established the efficacy of Time Pressure Management in a group of patients with traumatic brain injury. ${ }^{10}$ Currently a randomized controlled trial with stroke patients is being conducted. In this trial the effectiveness of Time Pressure Management is compared with the effects of a 'care as usual' approach to mental slowness in two groups of stroke patients. The case examples used in this paper were part of this randomized controlled trial. The results of the trial will be presented in an ensuing paper.

\section{Clinical messages}

- Patients that learn to use Time Pressure Management should have sufficient awareness of deficits and related problems, realize that the strategy is helpful and have adequate motivation to learn the strategy.

- Therapists that teach patients to use Time Pressure Management should adjust the training to the patients' individual learning abilities and cognitive skills. 


\section{References}

1 Gerritsen MJ, Berg IJ, Deelman BG, Visser-Keizer AC, Meyboom-De Jong B. Speed of information processing after unilateral stroke. $J$ Clin Exp Neuropsychol 2002; 25: 1-13.

2 Rasquin SM, Lodder J, Ponds RW, Winkens I, Jolles J. Cognitive functioning after stroke: a one-year follow-up study. Dement Geriatr Cogn Disord 2004; 18: 138-44.

3 Stuss DT, Stethem LL, Hugenholtz H, Picton T, Pivik J, Richard MT. Reaction time after head injury: Fatigue, divided and focused attention, and consistency of performance. $J$ Neurol Neurosurg Psychiatry 1989; 52: 742-48.

4 Ponsford JL, Kinsella G. Attentional deficits following closed head injury. J Clin Exp Neuropsychol 1992; 14: 822-38.

5 Winkens I, Van Heugten CM, Fasotti L, Duits AA, Wade DT. Manifestations of mental slowness in the daily life of stroke patients. Clin Rehabil 2006; 20: 827-34.

6 Milders M, Deelman B, Berg I. Rehabilitation of memory for people's names. Memory 1998; 6: 21-36.

7 Kaschel R, Della Sala S, Cantagallo A, Fahlbock A, Laaksonen R, Kazen M. Imagery mnemonics for the rehabilitation of memory: a randomized group controlled trial. Neuropsychol Rehabil 2002; 12: 127-53.

8 Geusgens C, Van Heugten C, Donkervoort M, Van den Ende E, Jolles J, Van den Heuvel W. Transfer of training effects in stroke patients with apraxia: an exploratory study. Neuropsychol Rehabil 2006; 16: 213-29.

9 Levine B, Robertson IH, Clare L et al. Rehabilitation of executive functioning: an experimental-clinical validation of goal management training. J Int Neuropsychol Soc 2000; 6: 299-312.

10 Fasotti L, Kovacs F, Eling PATM, Brouwer WH. Time Pressure Management as a compensatory strategy training after closed head injury. Neuropsychol Rehabil 2000; 10: 47-65.

11 Michon JA. Dealing with danger. Summary report of a workshop in the Traffic Research Centre, State University Groningen, The Netherlands, 1979.

12 Van Zomeren AH, Spikman JM. Tempo en aandacht (Speed and attention). In Vandermeulen
JAM, Derix MMA, Avezaat CJJ, Mulder Th, Van Strien JW eds. Niet aangeboren hersenletsel bij volwassenen (Acquired brain injury in adults). Elsvier Gezondheidszorg, 2003.

13 Ylvisaker M, Hanks R, Johnson-Greene D. Perspectives on rehabilitation of individuals with cognitive impairment after brain injury: rationale for reconsideration of theoretical paradigms. J Head Trauma Rehabil 2002; 17: 191-209.

14 Winkens I, Van Heugten CM, Fasotti L, Wade DT. Reliability and validity of two new instruments for measuring aspects of mental slowness in the daily lives of stroke patients. Neuropsychol Rehabil Published online, April 3, 2008.

15 Crosson B, Barco PP, Velozo CA et al. Awareness and compensation in postacute head injury rehabilitation. $J$ Head Trauma Rehabil 1989; 4: 46-54.

16 Sohlberg MM. Assessing and managing unawareness of self. Semin Speech Lang 2000; 21: $135-51$.

17 Gross Y, Schutz LE. Intervention models in neuropsychology. In Uzzell B, Gross Y. eds. Clinical neuropsychology of intervention. Martinus-Nijhof Publishers, 1986.

18 Wilson B, Herbert C, Shiel A. Behavioural approaches to neuropsychological rehabilitation. Psychology Press, 2003.

19 Siegert RJ, Taylor WJ. Theoretical aspects of goal-setting and motivation in rehabilitation. Review. Disabil Rehabil 2004; 26: 1-8.

20 Bergquist TF, Jacket MP. Awareness and goal setting with the traumatically brain injured. Brain Injury 1993; 7: 275-82.

21 Meichenbaum D. Cognitive behavior modification. An integrative approach. Plenum Press, 1977.

22 Mumford MD, Costanza DP, Baughman WA, Threlfall KV, Fleishman EA. Influence of abilities on performance during practice: effects of massed and distributed practice. J Educ Psychol 1994; 86: 134-44.

23 Cepeda NJ, Pashler H, Vul E, Wixted JT, Rohrer D. Distributed practice in verbal recall tasks: a review and quantitative synthesis. Psychol Bull 2006; 132: 354-80.

24 Geusgens C, Winkens I, Van Heugten C, Jolles J, Van den Heuvel W. The occurrence and measurement of transfer in cognitive rehabilitation: a critical review. J Rehabil Med 2007; 39: 425-39. 